\title{
Volume 26, Number 4
}

October 1994

\section{Journal of}
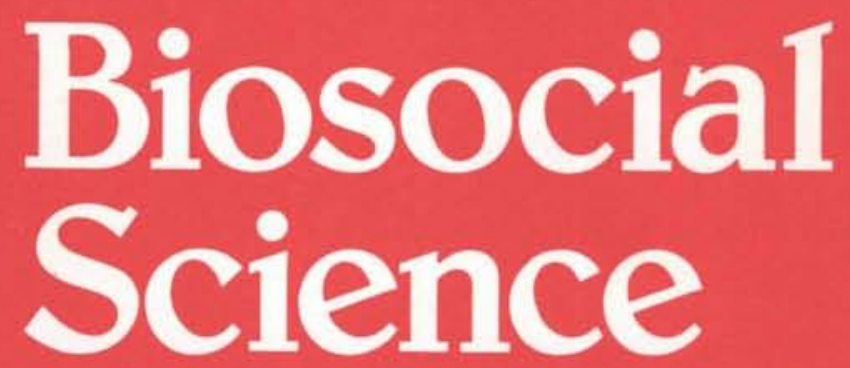

\section{Incorporating Biology and Society of the} Galton Institute

Published by the Biosocial Society

Cambridge, England 
Editor: C. G. N. Mascie-Taylor

\section{Editorial Advisory Panel}
J. L. Boldsen
D. A. Coleman
P. L. C. Diggory

\author{
G. A. Harrison \\ A. G. Hill \\ G. W. Lasker
}

D. M. Potts

P. F. Selman

I. Timæus
S. J. Ulijaszek

V. Reynolds

For the Galton Institute
J. A. Beardmore
R. Chester

\section{Review Editor \\ Erica Haimes}

Associate Editor

M. A. Herbertson

\section{Consultant}

D. F. Roberts

\section{Notice to Contributors}

The Journal of Biosocial Science publishes original papers, short reports; reviews, lectures, and book reviews dealing with social aspects of human biology, including reproduction and its control, gerontology, ecology, genetics and applied psychology; with biological aspects of the social sciences, including sociology, social anthropology, education and criminology: with social and biological elements of nutrition, growth and development, health and epidemiology; and with biosocial aspects of demography. Preference will be given to material which is clearly interdisciplinary.

Papers are considered for publication on the understanding that they have not been, and will not be, published elsewhere in whole or in part, and that, where customary, they have been approved for publication by the relevant Head of Department. The Editor is not responsible for any loss of or damage to manuscripts or illustrations and his decision on all editorial matters is final. This Journal is covered by Current Contents, Biological Abstracts, Psychological Abstracts and Population Index.

Manuscripts should be sent in duplicate to the Editor, Journal of Biosocial Science, Department of Biological Anthropology, Downing Street, Cambridge CB2 3DZ. They should be clearly typewritten, on one side of the paper only, with a $1 \frac{1}{4}$ inch margin, and be double-spaced and in the English language. Spelling should follow that of the Concise Oxford Dictionary. The Editor reserves the right to make minor literary emendations in the final editing, but manuscripts will not be altered substantially without consultation with the author or marked unless the paper is thought provisionally to be acceptable. The author is responsible for the accuracy of quotations, tabular matter and references. Manuscripts or tables prepared on dot-matrix printers are not acceptable.

Manuscripts should bear the title of the paper, name of the Institution where the work was done, the present postal address of the author if different from that of the Institution, and a short running head of not more than 50 letters. Titles should be brief. A short summary should precede the text. Acknowledgments should be made in a separate section.

Diagrams must be numbered and should bear the author's name, short title of the paper and figure number on the back. Captions should be typed on a separate sheet.

Tables should be typed on separate sheets, be given Arabic numbers and be headed by adequate captions. Their approximate position in the text should be indicated by a note in the margin. They should not exceed in size the equivalent of one page of print. Weights and measurements should be given in metric units. Standard abbreviations should be used $(\mu \mathrm{g}, \mathrm{mg}, \mathrm{g}, \mathrm{kg} ; \mathrm{ml}, \mathrm{l}$; $\mathrm{mm}, \mathrm{cm}, \mathrm{m}, \mathrm{km},{ }^{\circ} \mathrm{C}, \%,<,>, \mathrm{hr}, \mathrm{min}$ ). Abbreviations should not be followed by, and initials need not be separated by, full points (eg, FPA). Mean values should, where possible, be accompanied by standard errors or similar statistical indications of variance.

References in the text should be given in the manner that is standard in the Journal. Titles of journals should be abbreviated according to the World List of Scientific Periodicals, 4th edn (1964) and its supplements, and as also given in World Medical Periodicals. An unpublished paper should not be cited unless it is already in press.

Debate. A Debate section is reserved for comments on papers appearing in previous issues. Authors whose papers are involved will be given an opportunity to reply for simultaneous publications. The Editor's decision as to publication of comments is final. Comments, not exceeding 500 words (one printed page), should be sent to Editor.

Proofs will be sent to contributors for minor corrections, and should be returned to the Editor within one week. Major alterations to the text will be accepted only at the author's expense. The date of receipt given at the end of the paper is that on which the script as published was received or agreed.

Offprints. A copy of the issue of the Journal in which the paper appears will be supplied free to the author, or, where there are two or more, to the author responsible for ordering offprints. Offprints may be purchased by ordering on the form sent out with the proofs.

(c) Biosocial Society. With the exception of abstracts of no more than 300 words, no part of this publication may be reproduced or stored in a retrieval system in any form or by any means without the permission of both the Biosocial Society and the author. 


\section{JOURNAL OF BIOSOCIAL SCIENCE}

The Journal of Biosocial Science is published by the Biosocial Society and distributed by the Portland Press (formerly the Biochemical Society Book Depot).

Orders, payments and enquiries regarding distribution should be sent to:

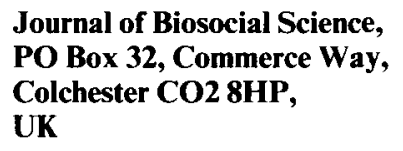

For 1995 (Volume 27) there will be four issues, published in January, April, July and October.

The subscription rates for 1995 are:

$\begin{array}{lcc}\text { Annual subscription } & \begin{array}{c}\text { UKerseas } \\ \text { overface mail) } \\ \text { (surface }\end{array} & \begin{array}{c}\text { USA, Canada } \\ \text { and Mexico } \\ \text { (by air) }\end{array} \\ \text { Per part } & £ 66.00 & \$ 126.00 \\ £ 20.00 & \$ 33.50\end{array}$

To avoid a break in continuity subscribers are asked to place their orders, either direct or through an agent, by mid-December. Should a Standing Order be required, this should be indicated in the order instructions and an invoice will then be sent automatically in the last quarter of each year.

Limited numbers of earlier issues are available. Volumes 1-10 (1969-78, original price $£ 111.50$ ) are offered to subscribers at the special price of $£ 52.00$ (US\$105.00) for the set.

Manuscripts for publication and books for review should be sent to:

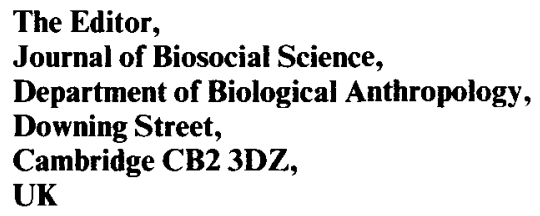

Second-class postage paid in Rahway, New Jersey, USA.

Postmaster. Send address corrections to: Journal of Biosocial Science, c/o Mercury Airfreight International Inc., 2323 Randolph Avenue, Avenel, NJ 07001, USA (US mailing agent). 


\section{JOURNAL OF BIOSOCIAL SCIENCE}

Vol. 26, No. 4

D. J. Adamchak

\section{J. A. Adetunji}

\section{A. Bideau \\ G. Brunet}

Marilyn Crawshaw

B. Desjardins

K. G. Dewey

Stephen M. Dixon

R. I. M. Dunbar

M. J. Heinig

W. Henke

Joan M. Herold

P. R. A. Hinde

Robert S. Hogg

Konia T. Kollehlon

C. G. N. Mascie-Taylor

M. C. Y. Mbago

M. T. Mbizvo

A. Meier-Koll

M. S. Mesa

Leo Morris

Akim J. Mturi

L. A. Nommsen-Rivers

Robert Peel

J. M. Peerson

D. F. Roberts

Emily Rousham

A. Sánchez-Andrés

Barbara Schardl

Peter Selman

Nancy J. Thompson

M. Solange Valenzuela
Contributors

October 1994

Professor, Department of Sociology, Kansas State University. Manhattan, Kansas, USA p. 553 Population Council/Bell Fellow, Center for Population and Development Studies, Harvard University, Cambridge, USA p. 469 Research Director, CNRS, Lyon, France p. 509 Professor, Université Lumière-Lyon 2, and Institut Européen des Génomutations, Lyon, France p. 509 Tutor in Social Work, Department of Social Policy and Social Work, University of York p. 563 Researcher, Département de Démographie, Université de Montréal, Canada p. 509 Professor of Nutrition, University of California, Davis, USA p. 517 Department of Psychology, University of Durham Professor, Department of Anthropology, University College London

Research Scientist, University of California, Davis, USA $\quad$ p. 565 Director, Institute of Anthropology, Johannes Gutenberg University, Mainz, Germany p. 562 Associate Professor, School of Public Health, Emory University, Atlanta, USA p. 427 Lecturer in Population Studies, University of Southampton p. 529 British Columbia Centre for Excellence in HIV/AIDS, Vancouver, Canada

p. 539

Associate Professor of Sociology, University of Maryland, Eastern Shore, USA p. 493 Head of Department of Biological Anthropology, University of Cambridge p. 567 Senior Lecturer, Department of Statistics and Demographic Unit, University of Dar es Salaam, Tanzania p. 451 Senior Scientist, Department of Obstetrics and Gynecology, University of Zimbabwe, Harare p. 553 Professor, Department of Psychology, University of Konstanz, Germany p. 479 Assistant Professor, Anthropology Section, Department of Animal Biology, Universidad Complutense de Madrid p. 441 Chief, Behavioral Epidemiology and Demographic Research Branch, Division of Reproductive Health, CDC, Atlanta, USA p. 427 Research Student, Department of Social Studies, University of Southampton p. 529 Research Scientist, University of California, Davis, USA p. 517 The Galton Institute, London p. 559 Statistician, Program in International Nutrition, University of California, Davis p. 517 Professor Emeritus, Department of Human Genetics, University of Newcastle upon Tyne p. 568 Lecturer, University of Western Australia, Perth p. 561 Lecturer, Department of Animal Biology, Universidad de Alcaia de Henares, Spain p. 441 Research Scholar, Department of Psychology, University of Konstanz, Germany p. 479 Lecturer in Social Policy, University of Newcastle upon Tyne p. 568 Assistant Professor, School of Public Health, Emory University, Atlanta, USA

p. 427 Instructor, Department of Health, University of Chile, Santiago p. 427 